\title{
TRATAMENTO PSICANALÍTICO COM BEBÊS E PAIS O QUÊ, POR QUÊ E QUANDO?
}

Björn Salomonsson

E-mailpara correspondência: bjorn.salomonsson@comhem.se

\section{RESUMO}

Este texto trata de princípios de um trabalho psicanalítico com pais e bebês, ilustrados por uma vinheta clínica. Aborda a elaboração da experiência de transferência-contratransferência e algumas funções da linguagem. Propõe que: é necessário falar com um bebê em sofrimento, ainda que ele não entenda o aspecto literal do que se diz; deve-se expressar acuradamente e sinceramente o que se considera serem as emoções pesadas da criança; a experiência de contratransferência, como expressa em encenações/enactments, metáforas e outros modos, pode indicar os níveis inconscientes da perturbação. 
Se você perguntar a um psicanalista em que seu trabalho consiste, ele não estará em apuros. Se ele achar difícil de responder, uma rica literatura pode ajudá-lo. Se perguntado por que uma pessoa angustiada deveria entrar em tratamento, suas experiências e pesquisas existentes mostram que a terapia pode ajudar as pessoas a lidar melhor com suas vidas. Quando ele deveria instituir a terapia? Essa questão é resolvida por sua agenda e as circunstâncias da vida do paciente e motivação terapêutica.

$\mathrm{Na}$ terapia psicanalítica pais-bebê, estas questões são mais complicadas. Tem ainda alguma coisa a ver com a "cura pela fala" de Freud? A mãe está falando, mas o bebê... De jeito nenhum! No entanto, muitos analistas têm experimentado um contato emocional com um bebê agitado. Norman (2001, 2004) chegou a afirmar isso foi essencial para o progresso terapêutico: a atenção do bebê foi capturada e seus afetos reprimidos surgiram, de forma lenta ou violentamente. Isso pode curar o trauma do bebê e ajudar a mãe a retomar o contato com seu filho. Ele ainda negou qualquer maior diferença entre esse trabalho e psicanálise clássica. Mas, o bebê não entende os significados lexicais de palavras, sua memória é pouco desenvolvida, e ele mal reconhece uma pessoa específica no terapeuta. Portanto, não podemos ignorar a questão "o que é este tratamento" dizendo: "é como qualquer outro modo de terapia, mas com três pessoas na sala". Para nos ajudar a formar uma opinião, eu vou apresentar um caso clínico como exemplo.

Palavras-chave: Psicanálise com pais e bebês, parentalidade, primeira infância.

\section{ABSTRACT}

This text deals with the principles of a psychoanalytic work with parents and babies, illustrated by a clinical vignette. It addresses the elaboration of the transference-countertransference experience and some language functions. It proposes that: it is necessary to speak to a suffering baby, even if he does not understand the literal aspect of what is said; one should express accurately and sincerely what is considered to be the child's heavy emotions; the experience of countertransference, as expressed in enactments, metaphors, and other modes, may indicate the unconscious levels of the disturbance.

Keywords: Psychoanalysis with parents and babies, parenting, early childhood.

\section{TINA E SUA MÃE NATHALIE}

No Centro de Saúde da Criança onde eu trabalho como clínico me pedem para ver Nathalie, uma mãe de três filhos. Sua filha de três meses de idade está gritando terrivelmente. Além disso, ela não consegue decidir sobre o nome da menina. Sua indefinição sobre esta questão a atormenta constantemente. Durante nossas entrevistas iniciais, eu tomo conhecimento sobre o passado de Nathalie; a 
preocupação de sua mãe com ela mesma, o caráter exigente de seu pai, e sua anorexia no momento do divórcio de seus pais quando ela tinha 17 anos. Depois de algumas entrevistas começamos a trabalhar duas vezes por semana. Vou fornecer material de duas sessões iniciais.

Durante a quinta sessão a menina está dormindo no carrinho de bebê. Nathalie me conta sobre o batismo no último sábado: "Finalmente, ela conseguiu seu nome, Christina Jennifer Martine! A bisavó do meu pai também foi chamado Christina. Martine vem da família de William (seu marido), enquanto Jennifer vem de mim mesma. Na verdade, eu queria que ela tivesse um nome que contém as letras $\mathrm{Na}$, para combinar com o meu nome Nathalie. Eu até fantasiei em ela levar o meu nome, mas isso seria estranho! Christina é bom. Afinal de contas, ele carrega algumas de minhas próprias letras”. Eu pergunto a ela como ela quer que eu chame a menina e ela responde Tina, o nome usado em casa. Ela relata que Tina está gritando menos agora, em comparação com quando a terapia começou. A mãe se ressente por não ser tão boa em confortar a filha como William.

Mãe: Ela tem seus ataques de gritos quando estamos prestes a dar um passeio. Assim que eu coloco o suéter nela é que tudo começa. Eu não entendo o porquê!

Analista: Poderia ter algo a ver com a forma como você está se sentindo sobre sair?

M: Eu não penso assim. Eu não sinto nada de especial. Talvez eu esteja tensa porque ela está tensa.

A: Algum tipo de círculo vicioso entre vocês. E quem sabe onde começa um círculo?

M: Sim. Seus gritos são terríveis. Na creche do meu filho, que eles chamam de "alarme de incêndio".

A menina acorda. Nathalie pega Tina com um sorriso e a coloca no colo. Tina e eu tenho contato olhos nos olhos por um minuto. Ela está com sono e sorri brevemente. Depois de dois minutos, ela começa a gritar. É um som terrível perfurando minha medula. Tenho a sensação de alguém perfurando minha cabeça e do meu cérebro balançando sobre em meu crânio. Nathalie está tensa.

Analista para Tina: Você está gritando terrivelmente e não sabemos por quê. Isso deve ser muito duro para você. Como estão as coisas para a mamãe?

Mãe: Eu me sinto mal por ela. Eu não entendo por que ela está gritando. Nessas situações, apenas o peito funciona. Mas não pode ser certo amamentar toda vez! 
A: Tina, eu também noto que você não olha a mamãe nos olhos. Você estava olhando para uma pintura na parede, mas quando seus olhos voltaram à mamãe você os fechou. Bem, na verdade, às vezes você espia a mamãe. Pergunto-me por que você não olha a mamãe diretamente nos olhos.

M: Sim, isso é certo. Eu me pergunto...

A. para Tina, ainda gritando: Tina, talvez você tenha duas mamães? Uma aparece quando você sorri alegremente para mamãe e a olha nos olhos. Outra que você não se atreve a olhar. Você parece ter medo dela.

M: Quando você menciona duas mamães penso em seus nomes Christina e Tina. Eles são tão diferentes. Tina soa agradável e acolhedor, enquanto Christina é mais ... Severo e antiquado. Mas também contém "Stina”, que eu acho que tem um ar suave. Eu a confundi chamando-a Christina e Tina. Eu estive brincando que ela vai se tornar esquizofrênica um dia.

A menina continua gritando. Mamãe não pode aguentar por mais tempo e oferece a Tina o seio. Ela o toma imediatamente. É uma cena calma e harmoniosa agora e eu acrescento:

Analista: Talvez haja uma terceira mamãe? Eu tive essa ideia agora que você, Tina, está parecendo sonolenta.

Talvez "mamãe-sonolenta" seria a terceira mamãe.

M: Eu acho que é tudo culpa minha. Após o nascimento ela sempre olhou nos meus olhos quando mamava. Mas eu estava verificando mensagens e e-mails no meu telefone celular ao amamentar! Sinto-me culpada por tê-la rejeitado e é por isso que ela não olhe em meus olhos!

Na sessão do dia posterior, a menina está mais calma e sorri para mim. Em seguida, ela retoma os gritos, mas sem aquele tom penetrante de ontem. Mamãe e eu começamos a usar "Tina" e "Christina", não só para indicar nome e apelido da menina, mas também para funcionar como metáforas para partes da personalidade de Nathalie. "Christina" refere-se a seus aspectos anoréticos, bem controlados e elegantes, enquanto que "Tina" refere-se a um aspecto confuso e espontâneo. Nathalie considera que é mais difícil de recuperar esta última parte dentro dela. Sugiro também para a menina que ela começa a gritar quando ela não consegue encontrar "Tina" no rosto de mamãe. Isto parece ocorrer principalmente quando Nathalie está bloqueando a "parte-Tina" dentro de si mesma. Ela confirma que ela sente o apelido da filha simplório e comum, que a faz se sentir envergonhada. Vamos agora mencionar uma cena registrada em vídeo para estudar a minha técnica mais de perto.

Vinheta do registro em vídeo de uma cena de atendimento: 
A menina está se acalmando lentamente. Sugiro à mamãe, gesticulando com as mãos, que ela tem essa poderosa parte-Christina, como uma armadura cobrindo a parte-Tina, que tem dificuldades de sair.

Bj: É difícil para você ser espontânea.

Bj Para Tina: você vê, mamãe fica dura quando ela está tentando consolá-la.

Bj a mamãe: você pode ouvir isso sem tomá-lo como uma acusação?

M: Sim. Quando ela está gritando ela não é perfeita, e eu quero que ela seja perfeita.

Bj: Pergunto-me, Tina, se mamãe também está brava com você. A Tina simples não é somente fofa, mas também brava algumas vezes.

M: Sim, ela parece brava.

Bj: Mas VOCÊ está brava?

M: Pelo menos eu tenho estado...

Bj: Você tem medo disto?

M: A gente não pode ficar brava com alguém tão pequena como Tina.

Björn. Toda mãe pensa dessa forma. (Para T): não é perigoso ficar brava com a sua mãe. Ou o inverso, ficando brava com você, Tina.

A menina ainda está gritando.

Bj: É interessante que hoje, Tina, você não está espiando. Você tem que começar a olhar para mamãe, ela é muito boa, você sabe, esta Christina-Tina-Mamãe de vocês. Mas ela também está brava com você, eu acho. E ela tem medo disto, porque não se fica brava com bebês pequenos.

Tina se acalma, a mamãe está balançando-a. Tina olha para mim, se acalma, grita novamente.

Bj: Agora o medo voltou. Nós vamos ter que ter calma e trabalhar sobre isso. Não há outro caminho. Isso é difícil para você, porque levamos isso a sério e você não recebe o peito imediatamente.

M: Não, e, além disso, dei o peito faz apenas um momento!

Bj: Não, Tina, eu não acho que você está com fome. Você tem fantasmas no seu interior. Isso é uma coisa terrível. Este Christina-Tina-fantasma.

M: Se eu tivesse apenas dado um nome instantaneamente! Sophie, por exemplo! Mas então eu teria oscilado entre Sophie e Sophia! Oh, Tina, você não tem uma mamãe cansativa...?! (Parecendo triste)

Tina se acalma.

Björn para Tina: Agora você está mais calma, você meio que entrou em si mesma. Parece bastante agradável. Mamãe pensa que ela é cansativa, você vê.

M: Muito cansativa! 
Bj: Você, veja (fazendo um gesto com a mão), mamãe tem uma pequena Tina no interior, e um grande Christina fora dela, mas às vezes a pequena Tina espreita através dela (deixo um dedo passar pela minha mão fechada). Pergunto-me se você, Tina notou isto na sua mamãe. Olha como você está seguindo meus dedos. E agora você estende a mão como se quisesse apertar a minha mão. Em seguida, você tende a desviar o olhar da mamãe, e isso é muito difícil para ela. É o pior castigo que existe, certo?

M: Sim!! Mas ela olha para mim também, e então eu sinto confirmada, e eu tenho pensamentos também.

Bj para T: Assim como você fez ao chegar aqui hoje, você estava deitada na mesa esperando para a mamãe para pegar suas coisas, e você estava olhando para mim e balbuciando. Agora você está olhando para as minhas mãos!

M: Ela é assim em casa, também, às vezes.

Bj: Não teria importância que nome você teria conseguido. Mamães têm esse problema de serem animadas, emocionais, espontâneas, como quando você está . . . plop! Você faz seu anúncio (Tina segue meus movimentos da mão). Sem iogurte açucarado, sem cookie de chocolate...!

M: Eu sou assim, bem chata! Se eu tivesse iogurte no café da manhã, eu não podia tê-lo para o almoço. É como não beber vinho tinto com peixe.

Bj: E há pessoas dizendo que é bastante OK ...

M: Não, não pode! Mas eu sei que as pessoas dizem isso.

\section{COMENTÁRIO SOBRE A VINHETA}

Que tipo de terapia foi isso, por que eu trabalho desta maneira, e quem foi/ foram o paciente(s) psicanalítico? Um paciente de terapia é alguém para quem endereçamos intenções inconscientes e fantasias, para ajudar a se familiarizar com eles e conectá-los com outros aspectos da sua pessoa, história de vida e as relações atuais. Nós também transmitimos nosso compromisso, atenção e atitude de não julgamento. Esta dupla hélice de promover um insight e transmitir aceitação constitui a terapia psicodinâmica.

Digo a Nathalie que ela tem uma armadura Christina cobrindo a parte-Tina, e que esta tem dificuldades em sair. Eu também digo que é difícil para ela ser espontânea, e eu pergunto se ela pode ouvir isso sem tomá-lo como uma acusação. Tais intervenções terapeutas fazem todos os dias, por isso espero nenhuma objeção se eu afirmar que eu estou fazendo terapia psicodinâmica com Nathalie.

E quanto a Tina? Eu interpreto suas representações inconscientes? Sim, por exemplo, quando eu digo "hoje, Tina, você não está espiando. Você tem que começar a olhar para mamãe, ela é muito boa, você sabe, este sua Christina-Tina- 
-Mamãe. Mas ela também está brava com você. E ela tem medo disto, porque não se deve ficar brava com bebês pequenos". Mas, Tina tem apenas 3 1/2 meses de idade e não sabe o que "muito bom" ou "espiar" significam. Talvez seja apenas a mãe que ouve e entende as minhas palavras e, em seguida, muda seu comportamento com seu bebê. Agora, o que Tina está ouvindo? Certamente o som das minhas palavras. Assim, eu poderia ter dito "blabla". No entanto, acho que ela também presta atenção aos meus movimentos faciais, gestos, tom de voz, ritmo da fala, e que ela tem alguma noção da minha sinceridade, vitalidade, criatividade e atenção. Se nos concentrarmos no primeiro grupo de marcadores semióticos, percebemos que minhas interpretações são construídas de várias modalidades de significação, de forma semelhante a uma ópera que consiste em mais do que a música ou as letras (Golse, 2006). Quando eu digo palavras como "brava” ou "muito bom", eu percebo minhas inflexões de voz diferenciais e exatas, meus movimentos corporais, e acho que Tina reage a eles.

Se eu dissesse "blabla" e fingisse tais variações, Nathalie iria querer saber o que eu estaria tramando, e Tina iria notar minha insinceridade, também - na verdade, não enquanto ela está gritando freneticamente, mas quando ela está mais no modo de audição. Para dar um exemplo de fora da clínica: Pense em uma mãe que consola seu bebê quando de repente é informada de que seu marido teve um acidente. Ela continua acalmar a criança, mas não ficaríamos surpresos se o bebê começasse a se incomodar. Para mim, os bebês são mais sensíveis à falta de sinceridade dos pais do que a tristeza, raiva ou medo expressos abertamente porque cria um duplo sentido, um racha entre as mensagens não-verbais e as verbais. Permitam-me citar o poeta sueco e Prêmio Nobel Tomas Tranströmer (2006):

De Março de 1979

Cansado de todos os que vêm com palavras, palavras, mas nenhuma linguagem Eu me encaminho para a ilha coberta de neve.

O indomado não tem palavras.

As páginas não escritas espalhadas por todos os lados!

Eu me deparo com rastros de cervos na neve.

Língua, mas não há linguagem.

Ou, nas palavras de Saint-Exupéry (1946), como a raposa ensina o Pequeno Príncipe para cativá-lo ou criar um vínculo: "Sente-se um pouco afastado de mim, na grama. Eu vou olhar para você com o canto do meu olho e você não vai dizer nada. A linguagem é uma fonte de mal-entendidos". 


\section{CONTRATRANSFERÊNCIA E CRIATIVIDADE}

Como vocês podem imaginar a partir do vídeo, a contratransferência é muitas vezes muito intensa neste tipo de trabalho. Este tópico merece uma longa digressão, então deixem-me ser breve. Contratransferência está, naturalmente, relacionado à empatia, que Bob Emde (1990) sugere ser semelhante "às experiências de mutualidade vividas na relação inicial mãe-filho" (p. 884). Serge Lebovici acrescentou que também envolve a criatividade; a empatia não é apenas sobre "sentir dentro" de nosso paciente, mas também sobre "esquecer-nos de nós mesmos" (2000, p. 227) e deixar os nossos processos associativos interagirem com os do paciente. Widlöcher (2001) chama isso de "cothinking/pensar com", um "processo de comunicação", envolvendo "o desenvolvimento recíproco da atividade associativa" (p. 254). Para Lebovici, empatia implica também algo de encenaçãolenactment e metáfora criada pelo analista. O incidente com minhas duas mãos simbolizando as partes Christina e Tina, e o dedo significando esforços da mãe em sair de sua prisão mental; estes são um ato criativo, uma encenação, e uma metáfora, tudo ao mesmo tempo. Em um nível menos sucinto, mas mais sugestivo, eu entoo, sorrio, olho severamente, suspiro, arranho meu pescoço, fico nervoso, desesperado ou aliviado. Eu acho que eles representam os meus esforços para diminuir a minha tensão interna, enquanto eu também tento me afastar um pouco para chegar a metáforas para descrever a colisão de duas mentes; uma de um bebê pequeno, outra da sua mãe.

Estes atos são todos enraizados no meu inconsciente e elaborados no meu pré-consciente. Como eu disse, Tina não entende o conteúdo lexical das minhas palavras, mas talvez "Esse cara está tentando me alcançar. Ele parece comprometido. Seu rosto se torna vivo. Os sons são saindo da sua boca, e os surpreendem - bem, a mim também. Ele parece sério e não angustiado, esperançoso e não desesperado, genuíno e não malicioso. Eu acho que ele é interessante". Eu acho que sua representação da mamãe é diferente; "Familiar, bem-intencionado, cheiro agradável, boa alimentadora, tensa, rosto duro, voz monótona, por favor, relaxe”!

\section{AS FUNÇÕES DA LINGUAGEM}

$\mathrm{Eu}$, portanto, argumento que (1) precisamos falar com um bebê em sofrimento, porém, (2) ele não vai entender o aspecto literal e, (3) devemos expressar acuradamente e sinceramente o que achamos que são as emoções pesadas da criança, e (4) a nossa contratransferência, como expressa em encenações/enactments, metáforas e outros modos, pode indicar os níveis inconscientes da perturbação. Françoise Dolto forneceu mais um argumento para nos endereçarmos ao bebê. Apesar de estar errada sua convicção de que um bebê capta o significado léxico de palavras, sua técnica de falar verdadeiramente (parler vrai) é um ponto importante. Pois, quem pode duvidar de que quando os pais escondem verdades 
embaraçosas isto pode perturbar o desenvolvimento do bebê? Por exemplo, Nathalie diz: "Quando ela está gritando, ela não é perfeita, e eu quero que ela seja perfeita". Eu, então, sugiro que ela também está irritada com sua filha e ela responde: "Pelo menos eu tenho estado zangada com ela - mas não se pode ficar com raiva de alguém que é tão pequena". A mãe tenta, assim, esconder essas vontades em vez de admiti-las e elaborá-las. Este é o oposto de vrai parler, esta é uma comunicação espúria, e acho que o bebê e mãe sofrem com isso.

Por que os pais embarcam em tal teatro? Dolto sugere que eles e seus filhos são apanhados em uma "teia complexa e ambígua de demandas e desejos em competição e conflito. Há pouca certeza sobre quem ou o que é bom ou suficientemente bom" (Bacon, 2002, p. 260). O self da criança é "fragmentário, mantido em conjunto e ganhando sentido não por uma 'verdade' interior, mas, como palavras em uma frase, por lei ou gramática ou força" (idem, grifo do autor). Minha razão para incluir o bebê em um diálogo verbal procede de uma extensão do argumento de Dolto: eu argumento que a linguagem vai ajudar a formar o bebê, porque pelo nosso "colocar palavras para o que ele está vivendo [linguagem] participa na fundação da sua estrutura [psíquica]" (Ledoux, 2006, p. 189) e, eu acrescentaria, autonomia. Precisamos conversar com a criança sobre seus desejos, "porque eles estão sempre justificáveis, mesmo que a pessoa não queira ajudá-la com eles" (Dolto, 1994, p. 108). Se nomearmos o desejo e o parearmos a uma proibição, implícita ou explícita, nós a ajudaremos a avançar ainda mais do que "a satisfação curto-circuito" que ela estava procurando. Portanto, "antes da idade de palavras, a presença de uma mãe que fala com o seu bebê é um alimento mais valioso do que o leite que ela oferece ao peito" (Dolto, 1994, p. 605).

Palavras sugerem ao bebê que uma ordem simbólica existe a qual, ao longo do tempo, vai ajudar a substituir o seu désir pelas demandas culturalmente aceitáveis. Mais tarde no desenvolvimento, ele vai começar a falar, a fim de "deslocar seu impulso" (Dolto, 1982, p. 48), por exemplo, dizendo "Mamãe boba, chame-me do que você quiser contanto que eu seja SEU bebê!" O pré-requisito é que ele passe por uma "castração simbolicogênica" e sofra "uma ruptura, uma separação da mãe" (de Sauverzac, 1993, p. 198 apud Dollander \& Tychey, 2004). Assim, palavras vão finalmente permitir-lhe dizer o que quer, detesta, ama e teme. De acordo com notícias recentes da Nathalie, Tina é hoje uma menina de quatro anos, que pode expressar opiniões pessoais e mostrar o seu amor por pais e irmãos.

Alguém poderia argumentar que Tina não pode diferenciar palavras de outros sons. No entanto, sabemos (Gervain, Macagno, Cogoi, Peña, \& Mehler, 2008) que os bebês consideram a fala como um modo especial de comunicação. O recém-nascido é mais sensível aos padrões de percepção típicos da fala dirigida a bebês, como mama e dada. Bebês de dois meses de idade mostram uma lateralização do cérebro semelhante à de adultos quando ouvem a fala (Gervain \& 
Mehler, 2010). Lactentes jovens também compreendem que as palavras, em contraste com outros sons, são usadas para categorizar objetos (Ferry, Hespos, \& Waxman, 2010). O desenvolvimento das vias neurais de processamento de fala no cérebro do bebê está agora muito bem mapeado (Sato et al., 2012; Homae, Watanabe, \& Taga, 2014). Para concluir (Marcus, Fernandes, e Johnson, 2007), "lactentes podem analisar a fala mais profundamente do que outros sinais, porque é altamente familiar ou altamente saliente, porque é produzida por seres humanos, porque é inerentemente capaz de suportar significado, ou porque carrega alguma propriedade acústica ainda não identificada que chama a atenção do sistema de regras por indução. Independentemente disso, desde o nascimento, os bebês preferem ouvir a fala a ouvir estímulos controle estreitamente alinhados" (p. 390). Posso, portanto, sentir-me razoavelmente certo de que Tina registra minha fala como uma forma especial de comunicação para a qual seu cérebro foi ligado desde há muito.

\section{TRATAMENTO PAIS-BEBÊ: QUANDO?}

Quando uma mãe expressa uma preocupação com seu bebê, devemos nos perguntar: É este um capricho ou um medo sustentado? Se não tiver certeza, consulte um terapeuta experiente! Durante a primeira consulta, ele/ela e a mãe podem estabelecer "qual é o problema" e decidir se este necessita de uma exploração mais profunda. A meu ver, essas consultas devem ocorrer em centros regulares de cuidado da saúde do bebê. Isso ajuda os pais a superarem seus sentimentos comuns de estigmatização.

Também precisamos considerar a condição do bebê. No meu projeto de pesquisa, que avaliou tais tratamentos, metade dos bebês expressou incômodo, chorou ou evitou os olhos ou seio da mãe em paralelo à sua angústia. Aqui, especialmente, recomendo um foco consistente sobre o bebê $e$ a mãe, ou, como disse Bion (1965), adotando uma visão binocular.

Para concluir, trouxe experiências e considerações teóricas de um modelo de terapia pais-bebê. Espero que eles forneçam alimento para o pensamento e para a discussão também de colegas que não são especificamente familiarizados com ela, mas que estão interessados em saber por que nós podemos falar com o bebê, que tipo de terapia esta é realmente, e quando se deve sugerir isso.

\section{REFERÊNCIAS}

Bacon, R. J. (2002). Winnicott Revisited: A point of view. Free Associations, 9B, 250-270. Bion, W. R. (1965). Transformations. London: Karnac Books.

Dollander, M., \& de Tychey, C. (2004). Affective development, education and prevention: A psychodynamic model. Psychoanalytic Review, 91, 257-270. 
Dolto, F. (1982). Séminaires de psychanalyse d'enfant, vol. 1 (Seminars on child psychoanalysis, vol. 1). Paris: Editions du Seuil.

Dolto, F. (1994). Solitude. Paris: Gallimard.

Emde, R. N. (1990). Mobilizing fundamental modes of development: Empathic availability and therapeutic action. Journal of the American Psychoanalytic Association, 38(4), 881-913.

Ferry, A. L., Hespos, S. J., \& Waxman, S. R. (2010). Categorization in 3- and 4-month-old infants: An advantage of words over tones. Child Development, 81, 472-479.

Gervain, J., Macagno, F., Cogoi, S., Peña, M., \& Mehler, J. (2008). The neonate brain detects speech structure. Proceedings of the National Academy of Sciences of the United States of America, 105, 14222-14227.

Gervain, J., \& Mehler, J. (2010). Speech perception and language acquisition in the first year of life. Annual Review of Psychology, 61, 191-218.

Golse, B. (2006). L'être-bébé (The baby - a Being). Paris: Presses Universitaires de France.

Homae, F., Watanabe, H., \& Taga, G. (2014). The neural substrates of infant speech perception. Language Learning, 64(Suppl 2), 6-26.

Lebovici, S. (2000). La consultation thérapeutique et les interventions métaphorisantes (The therapeutic consultation and the metaphorizing interventions). In: M. Maury \& M. Lamour (Eds.), Alliances autour du bébé. De la recherche à la clinique (Alliances around the baby. From research to clinic), p. 250. Paris: Presses Universitaires de France.

Ledoux, M. H. (2006). Dictionnaire raisonné de l'oeuvre de F. Dolto (A commented dictionnary on the work of F. Dolto). Paris: Payot \& Rivages.

Marcus, G. F., Fernandes, K. J., \& Johnson, S. P. (2007). Infant rule learning facilitated by speech. Psychological Science, 18(5), 387-391.

Norman, J. (2001). The psychoanalyst and the baby: A new look at work with infants. International Journal of Psychoanalysis, 82(1), 83-100.

Norman, J. (2004). Transformations of early infantile experiences: A 6-month-old in psychoanalysis. International Journal of Psychoanalysis, 85(5), 1103-1122.

Salomonsson, B. (2014). Psychoanalytic therapy with infants and parents: Practice, theory and results. London: Routledge.

de Saint-Exupéry, A. (1946). Le Petit Prince. Paris: Gallimard.

Sato, H., Hirabayashi, Y., Tsubokura, H., Kanai, M., Ashida, T., Konishi, I., . . Maki, A. (2012). Cerebral hemodynamics in newborn infants exposed to speech sounds: A whole-head optical topography study. Human Brain Mapping, 33(9), 2092-2103. de Sauverzac, J. F. (1993). Françoise Dolto. Paris: Champs Flammarion.

Tranströmer, T. (2006). The Great Enigma. New collected Poems (R. Fulton, Trans.). London: New Directions.

Widlöcher, D. (2001). The treatment of affects: An interdisciplinary issue. The Psychoanalytic Quarterly, 70(1), 243-264. 
